\title{
Editorial
}

\section{A Strong Field and a Deserving Winner}

Medical History is delighted to announce the winner of the 2014 William Bynum Prize: Clare Leeming-Latham's wonderful essay titled 'Unravelling the "tangled web": Chemotherapy for Tuberculosis in Britain, 1940-70'. We are also pleased to announce a set of joint runners up: Elisa González ('Nurturing the Citizens of the Future: Milk Stations and Child Nutrition in Puerto Rico, 1929-60') and Anne Hanley ('Venereology at the Polyclinic: Postgraduate medical education among general practitioners in England, 1899-1914').

The prize committee was chaired by Professor William Bynum, and also included Professor Alison Bashford, Dr Joanna Radin, Professor Andrew Scull and Dr Laurence Totelin. We had an extraordinarily strong field. Out of the eleven entries, six are showcased in this issue (these essays sit alongside the piece by Katherine A. Walker, who was a runner up in the 2013 Bynum Prize competition). Based on the reports received, a further four entries submitted in 2014 have been asked to revise and resubmit for potential future publication. Only one essay did not meet the standard required for publication.

Our congratulations to all these young scholars - all of us, Professor Bynum included, were impressed with the range of tremendous work on display.

\section{SANJOY BHATTACHARYA}

Department of History, Centre for Global Health Histories, University of York, UK

Email: sanjoy.bhattacharya@york.ac.uk 